\title{
An Empirical Study on the Countermeasures of Implementing 5G Multimedia Network Technology in College Education
}

\author{
Ke Li $\mathbb{D}^{1}$ and Sang-Bing Tsai $\mathbb{D}^{2}$ \\ ${ }^{1}$ College of Physical Education, Henan University of Technology, Zhengzhou 450001, Henan, China \\ ${ }^{2}$ Regional Green Economy Development Research Center, School of Business, WUYI University, Nanping, China
}

Correspondence should be addressed to Ke Li; likehngy@126.com and Sang-Bing Tsai; sangbing@hotmail.com

Received 1 September 2021; Revised 22 September 2021; Accepted 28 September 2021; Published 13 October 2021

Academic Editor: Zhiyong Yu

Copyright (c) $2021 \mathrm{Ke} \mathrm{Li}$ and Sang-Bing Tsai. This is an open access article distributed under the Creative Commons Attribution License, which permits unrestricted use, distribution, and reproduction in any medium, provided the original work is properly cited.

\begin{abstract}
Aiming at the problem of $5 \mathrm{G}$ multimedia heterogeneous multimodal network representation learning, this paper proposes a collaborative multimodal heterogeneous network representation learning method based on attention mechanism. This method learns different representations for nodes based on heterogeneous network structure information and multimodal content and designs an attention mechanism to learn weights for different representations to fuse them to obtain robust node representations. Combining the general process of exploring the college physical education model and the characteristics of the multimedia network classroom environment, this article constructs the process of exploring the college physical education teaching model of the multimedia network classroom. Through the research and practice of the inquiry college physical education teaching model in the multimedia network classroom, it is verified that the implementation of the inquiry college physical education teaching in the multimedia network classroom can effectively influence and increase the students' interest in learning and stimulate the students' inner learning motivation. Through the guidance and training of teachers, a variety of disciplines can be used to carry out college physical education in multimedia network classrooms, so that the integration between courses can be truly realized, with the aim that all courses can share the excellent results brought by the development of modern education technology. More educators understand, accept, and participate in the practice of college physical education based on multimedia network classrooms and better serve the education of college physical education. The construction of the college physical education evaluation system should be combined with the characteristics of the $5 \mathrm{G}$ multimedia network era. The evaluation process includes data collection, data analysis, result output, and result feedback. Each link is an indispensable part of the college physical education evaluation process. Based on the relevant knowledge of the $5 \mathrm{G}$ multimedia network, the evaluation indicators determined in this study can basically reflect the various elements of the physical education process in colleges and universities. The distribution of index weight coefficients is more scientific and reasonable. Compared with the current system, the college physical education evaluation system constructed by exploration has a certain degree of objectivity and scientificity. Therefore, it is feasible to apply the 5G multimedia network to the evaluation of college physical education.
\end{abstract}

\section{Introduction}

With the development of the global economy, science and technology have achieved unprecedented development under the impetus of this economic wave [1]. First, computer information technology has been widely popularized and applied, which then led to the emergence and development of Internet technology, as shown in the background of the previous topic selection. The Internet has such a large audience in our country, so it can be seen that human society has entered a new era of knowledge and network. The popularization and application of the Internet and the development and application of new multimedia technologies have provided a new way of modern college physical education [2]. The combination of the two has given rise to the multimedia network college physical education teaching technology, which serves as a multimedia network college physical education teaching. The carrier of technology in the 
process of college physical education can be called a multimedia network college physical education platform. Multimedia network college physical education is open and interactive at the same time, and these are incomparable to traditional college physical education. It is known for its rich resources and powerful functions and emphasizes that students are the main body, so as to run through the entire process of physical education in colleges and universities. The multimedia network college sports teaching platform provides students with a more intuitive and visualized learning platform with real-time interaction [3]. All these are in line with the direction of the development and reform of physical education in modern education colleges.

Through the investigation and analysis of the latest information released by relevant authoritative websites on the Internet, it is found that the construction and development level of my country's multimedia network college sports teaching platform is obviously unevenly distributed [4]. The construction and development of the multimedia network college physical education platform in the economically developed eastern and central regions and some colleges and universities have begun to take shape, while some economically underdeveloped western regions and most colleges and universities' multimedia network college physical education platforms are still in the early stages of exploration. In the development and construction, there are still many regions and universities that have not developed and constructed the multimedia network college sports teaching platform. Although many colleges and universities have their own campus networks, they only use their campus websites as information publishing and downloading platforms and do not have a complete set of multimedia network college physical education teaching systems [5]. However, in the surveyed colleges and universities that have applied the multimedia network college physical education platform, the use of the multimedia network college physical education platform is basically limited to the main subjects of the colleges and universities, and as some nonsports special subject colleges, the part used in college physical education in colleges and universities is very few.

Aiming at the heterogeneity, sparsity, and multimodality of $5 \mathrm{G}$ multimedia network data, a multimodal heterogeneous network representation learning model based on attention collaboration is proposed. The model uses metapaths to capture hidden structural information and multimodal content information in heterogeneous multimodal networks and learns node representations based on structural information and content information, respectively. We propose a collaborative framework based on the attention mechanism to fuse the structural representation and content representation of nodes to obtain a robust node representation. Based on the theoretical basis of exploring the teaching mode of college physical education in the multimedia network classroom, this article analyzes the characteristics of exploring the teaching mode of college physical education and the multimedia network classroom. Combining the general process of exploring the college physical education model and following the design principles, this article constructs a flow chart of college physical education teaching design that explores the college physical education model of a multimedia network classroom and analyzes and elaborates the flow chart in detail. Under the guidance of the teaching principles of college physical education and the design process of college physical education, the whole process of college physical education implementation is demonstrated with college physical education teaching cases. The construction of the college physical education evaluation system should be combined with the characteristics of the $5 \mathrm{G}$ multimedia network era. The evaluation process includes four major links: data collection, data analysis, result output, and result feedback. Data collection must be comprehensive, data analysis methods must be scientific, and the output of the results must be accurate. The feedback of the results should be disclosed in time. Based on the relevant knowledge of the $5 \mathrm{G}$ multimedia network, the evaluation indicators determined in this study can basically reflect the various elements of the physical education process in colleges and universities.

\section{Related Work}

The United States is recognized as the earliest and most advanced country in the development of multimedia network college physical education teaching and the most extensive use of multimedia college physical education teaching [6]. According to a survey conducted by the U.S. Federal Department of Education on the physical education teaching of multimedia networked colleges and universities in American secondary education institutions, 1,690 of the 5,020 primary and secondary schools in the United States provide physical education courses in online colleges and universities. This data accounts for $34 \%$ of the total number of primary and secondary schools. Approximately 660,000 students have registered and are willing to participate in multimedia network college physical education teaching. This data accounts for approximately $11.6 \%$ of the total number of students in primary and secondary schools (approximately 14.34 million) [7]. Regarding college physical education teaching, schools that use multimedia college physical education, such as California Virtual University, Michigan Virtual University, American Electronic University Network, and Jones International University as representative universities, even completely abandon the traditional college physical education concept; all are computer and server.

Early foreign universities that used network technology to teach physical education in colleges include Stanford University in the United States and the University of Southern Queensland in Australia. The continuous deepening of the application of network technology to college physical education has gradually become an important component of college physical education and at the same time has become the direction of the modern development of college physical education. At present, the research results of college physical education in foreign colleges and universities under the network environment, as well as the research of college physical education teaching models, are still in the initial stage. However, with the continuous 
development of network technology and the positive improvement of college physical education courses, the use of network technology in college physical education will be effectively promoted, and related college physical education research will also be continuously strengthened.

In terms of the application of network technology to college physical education in colleges and universities, the Massachusetts Institute of Technology in the United States used electronic sports teaching materials in college physical education as early as 2001 and passed the college physical education content of various sports in college physical education [8]. It also builds a network platform for college physical education assessment, which facilitates students to remotely learn through the Internet in a timely manner, assists in sports training and other college physical education contents, and realizes functions such as online examinations, which fully reflects the modern technology of college physical education. Features realize the diversification of college physical education forms and greatly improve the flexibility of college physical education.

Relevant scholars analyzed the application of modern educational technology in college physical education by using the literature method and logical analysis method and pointed out that modern computer network technology provides a brand-new platform for college physical education in colleges and universities [9]. This kind of platform is used in college physical education. Application is the inheritance and development of traditional college physical education. The promotion of new multimedia network technology in college physical education not only promotes the transformation of college teachers' concepts of college physical education but also optimizes college physical teaching theory, college physical teaching methods, college physical teaching evaluation, and technical and tactical college physical teaching. Relevant scholars summarized the characteristics of physical education in schools and colleges and then analyzed the advantages and disadvantages of traditional physical education models in colleges and universities, thus leading to the application of online college physical education technology in college physical education [10]. Finally, it is pointed out that network college physical education has solved the problem of short class hours in traditional college physical education and has broken through the limitation of time and space. The development of multimedia network technology makes it easier to achieve the goals of college physical education [11].

The researchers explained the drawbacks of traditional physical education courses, and the more difficult technical movements could not be fully demonstrated [12]. The personal quality of teachers affects the quality of physical education in colleges and universities. The process of physical education in colleges and universities cannot be personalized with students as the theme. The process of physical education in colleges and universities is restricted by weather venues and equipment. The author believes that these are the shortcomings of traditional physical education in colleges and universities. The emergence of multimedia network college physical education has just made up for these shortcomings. The multimedia display of multimedia network college physical education teaching can more vividly decompose and display the more difficult technical actions and can realize good human-computer interaction and truly achieve the theme of students $[13,14]$. The personalized college physical education, the rich resources of the multimedia network, and the large amount of information can better accomplish the goals of college physical education. The author believes that the development of multimedia network college physical education in college social sports majors is an optimization of traditional college physical education teaching methods [15].

Relevant scholars discuss from the perspective of the rich network resources of multimedia network college physical education teaching $[16,17]$. It describes the shortcomings of multimedia network college physical education in using network resources to improve the existing traditional college physical education teaching. The abundance of network resources can stimulate students' independent learning and interest in physical education courses [18-20]. The multimedia network college physical education teaching can be based on students. To carry out effective and reasonable personalized college physical education, in terms of technology, multimedia network college physical education can use modern multimedia technology to simulate realistic scenes and help students establish a clear representation of actions [21-23]. Finally, the author made an explanation of the rational use of network resources to improve physical education in colleges and universities.

\section{5G Multimedia Heterogeneous Multimodal Network Representation Learning Method}

3.1. Distributed Architecture of the 5G Wireless Backhaul Network. In order to realize the transmission of wireless backhaul traffic in the $5 \mathrm{G}$ ultradense cellular network, the distributed architecture of the wireless backhaul network is usually adopted, as shown in Figure 1. A macrobase station is located in the center of a macrocell with a radius of $R$ and controls the infinite backhaul routing of small cell base stations within the coverage of the macrocell. Within the coverage of the macrocell, $n=M+N$, small cell base stations are randomly and densely deployed. Among them, $M$ small cell base stations connected to the core network through fiber-to-cell links are configured as backhaul gateways, whose main function is to forward backhaul traffic to the core network; the other $\mathrm{N}$ small cell base stations forward their backhaul traffic to $M$ backhaul gateway. In this scenario, it is assumed that the millimeter wave transmission technology is used to transmit wireless backhaul traffic, each small cell base station has enough bandwidth for wireless backhaul transmission, and the backhaul traffic of the small cell base station is forwarded to the backhaul gateway through a multihop relay mechanism. Because the millimeter wave has strong directivity, the millimeter wave wireless backhaul network does not need to consider the interference of neighboring transmitting nodes.

Due to the characteristics of millimeter wave path loss and obvious scattering effect, it is assumed that the one-hop distance of wireless backhaul transmission does not exceed 


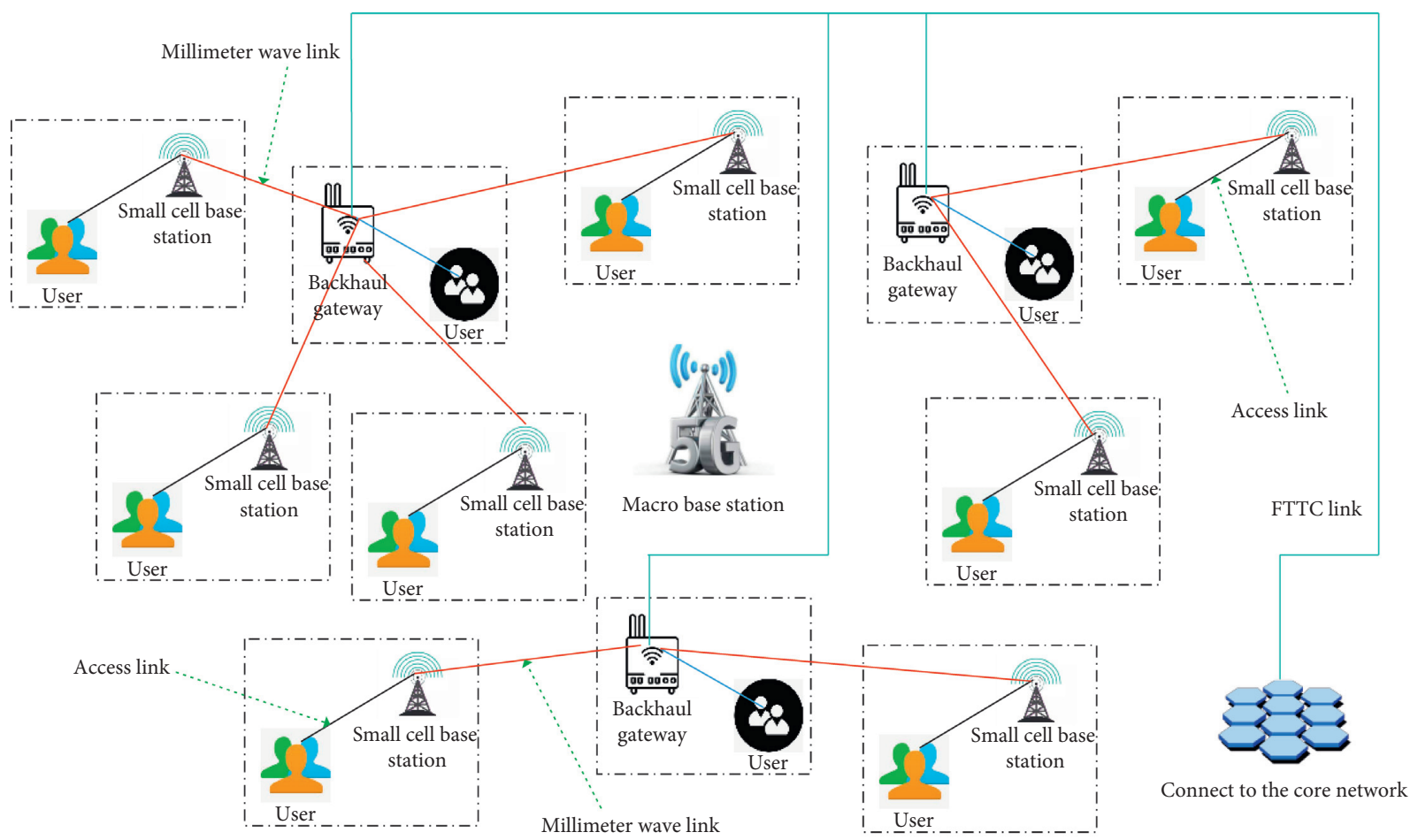

FIgURE 1: Distributed architecture of the 5G ultradense cellular network.

D0; that is, each small cell base station can only connect to the base station in the coverage area with the base station as the center and the radius of D0. Since the future $5 \mathrm{G}$ cellular network will be dense or even superdense, by setting the location of the backhaul gateway reasonably, we can think that $N$ ordinary small cell base stations can send data to the corresponding backhaul gateway node (Figure 1).

3.2. Node Representation Learning Method Based on the Heterogeneous Network Structure. Figure 2 shows the framework of the A2CMHNE method. We propose a metapath-based method to mine the implicit structure information in heterogeneous networks and design two representation learning methods to learn the text description and image feature representation in the network, respectively, so as to make full use of the multitude in the network. Finally, the attention-based collaboration mechanism is used to integrate these three representations, so that the structural information and multimodal content information of the network can be fully utilized to alleviate the sparsity of the network and finally build a robust node representation (Figure 2).

We design a loss function based on a heterogeneous network structure, and the implicit structure information captured by the metapath can be retained as much as possible in the representation of the constraint node. Given a metapath mode mps, we can capture zero or several metapath neighbors for node $v_{i}$. We denote the set of neighboring nodes of the metapath of the node $v_{i}$ in the metapath mode mps as $\operatorname{Nmps}\left(v_{i}\right)$. We model the conditional probability distribution of the neighboring nodes of the metapath:

$$
p_{\text {mps }}\left(v_{j} \mid v_{i}\right)=\exp \left(c_{j s}\right) \bullet \exp \left(x_{i s}\right) \bullet \frac{\left(t_{l}+1\right) \bullet V_{t l}}{\exp \left(c_{k s}\right) \bullet \exp \left(x_{j s}\right)}
$$

Here, $x_{i s}$ is the representation of the node $v_{i}, c_{j s}$ is the representation of the context of the node $v_{j}, t_{1}$ is the type of the tail node specified by the metapath mode mps, and $V_{t l}$ represents the collection of nodes of the type $t_{1}$. The context of the node here refers to the neighboring node of the metapath of the node. The core idea of the formula is that if the context distribution of two nodes is similar, then the two nodes themselves tend to be similar.

3.3. Node Representation Learning Method Based on Multimodal Content. In order to utilize the multimodal content information associated with nodes in the $5 \mathrm{G}$ multimedia network, we learned two content representations for nodes: node representation based on text content and node representation based on visual content. In a $5 \mathrm{G}$ multimedia network, some nodes may be accompanied by rich text content information such as text descriptions. We use the words in these text content as nodes and together with the original nodes form a heterogeneous text network:

$$
G_{t}=\left\{E_{\mathrm{tc}} V_{\mathrm{tc}}\right\} .
$$

Similar to the idea of considering the context distribution of neighboring nodes of a metapath, we consider the distribution of text nodes associated with ordinary nodes to construct a loss function based on text content, as shown in the following formula: 


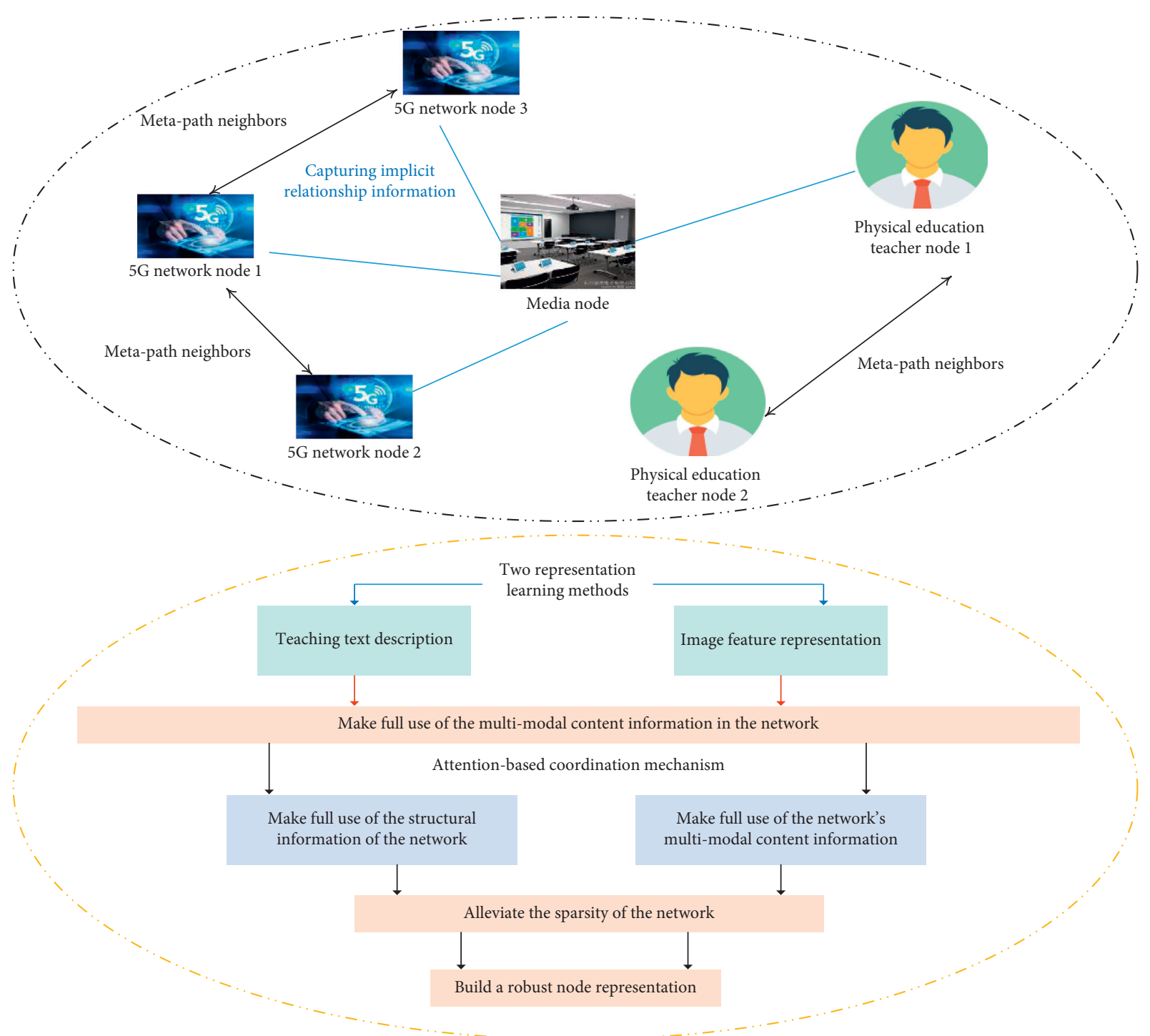

FIGURE 2: Overall framework diagram of node representation based on heterogeneous network structure.

$$
L_{\text {text-content }}=V_{t c} \bullet \log p_{t c} v_{i} \bullet \log p_{t c} v_{j}
$$

The same words in different text contents correspond to the same node in the graph; otherwise, the distribution of associated text nodes will become meaningless. By optimizing the loss function $\mathscr{L}$ text-content, we can learn node representation based on text content for node $v_{i}$.

When considering text content, the distribution of text nodes is meaningful because it is very common for different text contents to share text nodes (that is, contain the same words). But the visual information is very different. The visual information contained in different nodes rarely overlaps. Although in social networks and other scenarios, different articles may contain the same pictures, only considering this situation will ignore most of the visual information. If the original node and image are used to construct the network directly, most image nodes will only contain one neighbor node. Therefore, it is not feasible to construct the network directly from the original nodes and images and to learn the visual representation of the nodes based only on the structural information of the constructed network.

The content of the image itself contains rich semantic information. We can encode the image content to extract feature representations through mature technologies such as convolutional networks. Although image nodes are not shared, we can use a shared convolutional network as an encoder to extract image features to learn the representation of image nodes. We put each image as a node into the original heterogeneous network and use the deep encoder and metapath to use the content information of the image and the structure information of the heterogeneous network, respectively, and finally learn the representation of the image node. For each image node $v_{i}$, we use ResNet pretrained on ImageNet to extract its visual content features $f_{i}$.

$$
L_{\text {visual-content }}=\log p_{v c} \frac{v_{i}}{v_{j}} \bullet N_{\mathrm{mps}} .
$$


We construct the visual content loss function based on the encoding result and the neighboring nodes of the metapath, as shown in the following formula:

$$
L_{\text {visual-content }}=\log p_{v c}\left|v_{i} \bullet v_{j}\right| \bullet\left(v_{j}+N_{\text {mps }}\right) \text {. }
$$

In the formula, $v_{i}$ is the image node, and $v_{j}$ is the neighboring node of the metapath of $v_{i}$ in the metapath mode. Since most image nodes have only one neighbor in the network, we use metapaths to expand their contextual information. By optimizing the image loss function $\mathscr{L}_{\text {visual-content }}$, we can get the representation of the image node. A common node may contain multiple pictures; that is, multiple image nodes will be associated. We use the average value of these image nodes as the image representation of the node.

3.4. Attention-Based Node Representation Coordination Mechanism. By optimizing the loss function $\mathscr{L}_{\text {structure, }}$ $\mathscr{L}_{\text {text-content, }}$ and $\mathscr{L}_{\text {visual-content, }}$ we can obtain a node structure represented by $x_{i s}$ and multimodal content representation:

$$
x_{i c}=\left\{\begin{array}{ll}
x_{i v c} & x_{i t c}
\end{array}\right\}
$$

We propose an attention-based collaboration mechanism to integrate these several representations to build a robust node representation. For each node, the structure information, text content information, and visual content information of the node have different importance to the semantics of the node. In addition, for different nodes, the distribution of the importance of this information is different. Therefore, we dynamically calculate the importance of different types of representations for each node.

Our collaboration mechanism can focus more on information that is more relevant to node semantics. Based on these different representations and corresponding weights, we can construct a robust node representation by the method shown in the following formula:

$$
x_{i}=x_{i v c} \lambda_{i v c}-x_{i t c} \lambda_{i t c}-x_{i s} \lambda_{i s} .
$$

For different nodes, the importance distributions of the corresponding multiple representations may be different. To this end, we introduced a self-attention mechanism to dynamically calculate the importance weight information for each node. For each node $v_{i}$, we will vertically stack its corresponding structure representation $x_{i s}$, text content representation $x_{i t c}$, and visual content representation $x_{i v c}$ to form a representation matrix $M_{i}$. Based on $M_{i}$, we use the following formula to calculate the incidence matrix $A_{i}$ to reflect the relationship between different representations of nodes:

$$
A_{i}=H\left(M_{i}\right) \bullet G\left(M_{i}\right)^{T} .
$$

In the formula, $G\left(M_{i}\right)$ and $H\left(M_{i}\right)$ represent two different fully connected layers, which can transform the d-dimensional eigenvector of each row in the input matrix into a new d-dimensional eigenvector and use the ReLU activation function to perform activation.

\section{5G Multimedia Network Classroom Explores the Design and Implementation of the College Sports Teaching Mode}

Under the guidance of educational theory, combined with the exploration of the general process of college physical education mode and the characteristics of the multimedia network classroom environment, and in accordance with the design principles of college physical education teaching, the teaching mode in the multimedia network classroom can be constructed. It is carried out in a multimedia network classroom environment. Under the guidance of teachers, students actively explore the essence, grasp the main points of knowledge, and take the self-inquiry of students as the mainline of the exploratory college physical education teaching model.

Under the guidance of the teacher, we make full use of the functions of the multimedia network classroom environment and the organic integration of the curriculum, allowing students to observe, think, and search online to discover knowledge and design through the creative application of various tools provided by the multimedia network classroom. Figure 3 shows the design process of multimedia network classrooms exploring college physical education teaching (Figure 3 ).

4.1. Investigation to Determine the Target of Exploration. To carry out college physical education in a multimedia network classroom, due to the changes in the college physical education environment, teachers and students are required to have a certain level of information technology application ability to adapt to this technical classroom. Before implementing the exploration of the college physical education model in multimedia network classrooms, it is necessary to investigate the ability and level of teachers and students to apply information technology, so as to carry out corresponding training for teachers and students according to needs. In addition, it is also the primary consideration for teachers to explore the college physical education design by investigating to understand the cognitive level of students and determining the exploration goal.

The determination of the exploration goal should be based on the systematic analysis of the college physical education content, and it cannot be decided arbitrarily. Generally speaking, the key content should be explored, but not all content is suitable for inquiry, and teachers should make good choices. It also depends on what kind of inquiry abilities can be cultivated by this part of the content and the significance of these inquiry abilities to student development. Students' study preparation and study characteristics are also an important basis for determining the exploration goals. In addition, when determining the exploration goals, we must also consider making full use of the various functions of the multimedia classroom in order to achieve the best college physical education results. Teachers need to make adequate preparations before determining the exploration goals, that is, to prepare the lessons. Specific requirements are as follows. 


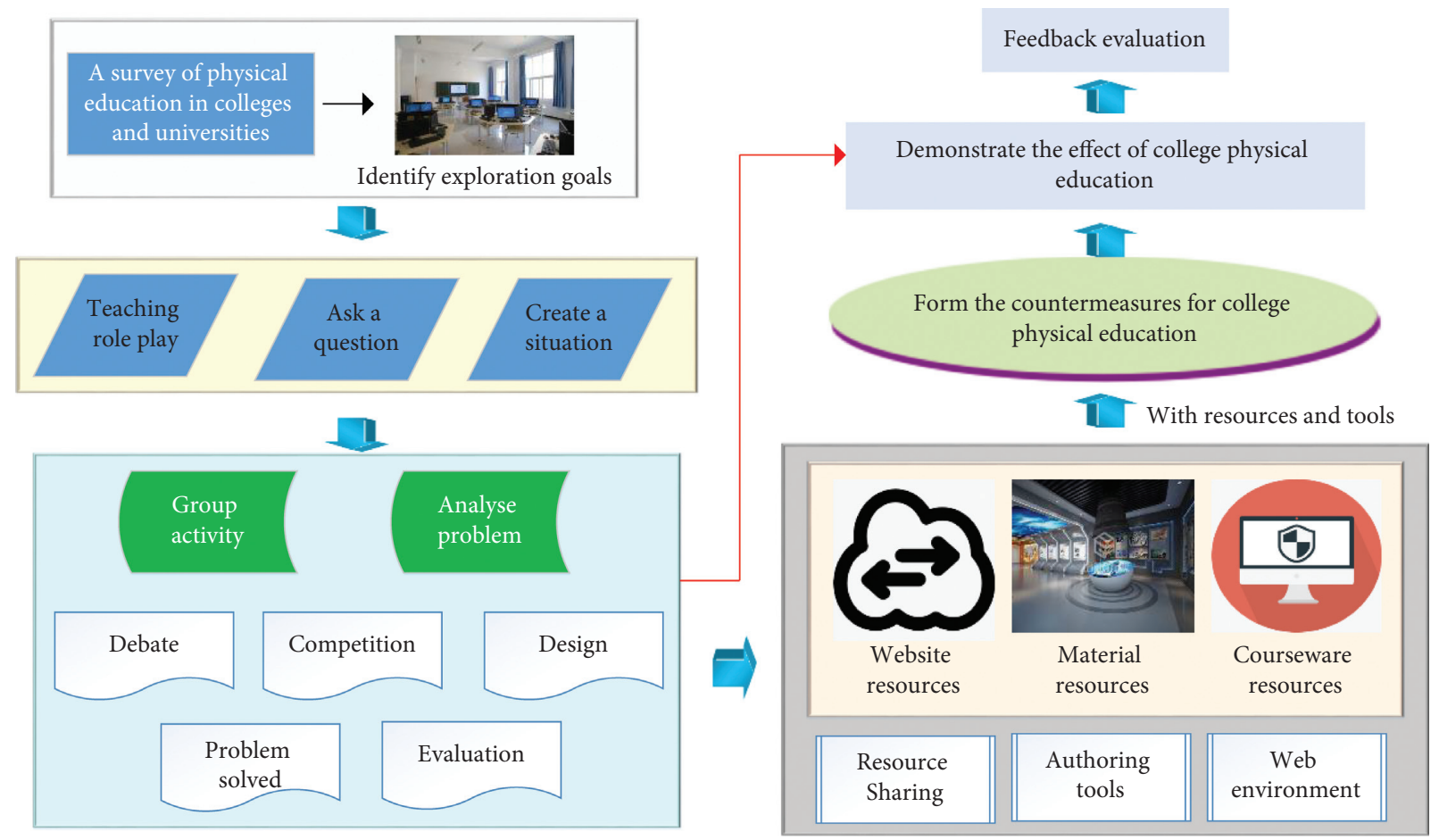

FIGURE 3: Inquiry into the flow chart of physical education teaching design in colleges and universities in the multimedia network classroom.

4.1.1. Preparation of Teaching Materials. Teachers should fully understand the content of the textbooks, delve into the textbooks, and understand the materials related to the content of college physical education in this course, in order to be a good tutor, help, facilitator, and academic advisor for students.

4.1.2. Preparation of Students. Teachers should understand the learning characteristics of students with different age characteristics and make corresponding investigations on the students' existing knowledge and skills, so that they can be targeted when determining the exploration goals.

4.1.3. Preparation of the Environment. Teachers should be familiar with the learning environment of the multimedia network classroom. First of all, we must understand some precautions for carrying out college physical education in multimedia network classrooms; for example, dust will generate static electricity and cause equipment failure; abnormal weather will damage equipment (too high or too high humidity, room leakage, etc.); the intensity of light will affect vision; the maintenance of computers and network equipment takes time and effort and requires professionals to maintain. Secondly, teachers should be familiar with the various functions of the multimedia network classroom in order to better carry out physical education in colleges and universities, such as group presentation, monitoring rebroadcasting, rebroadcasting, monitoring tutoring, screen recording, and other functions. Third, teachers should be familiar with commonly used computer software and be able to use this software to make electronic teaching plans with rich pictures, content-rich courseware, animations, etc.

4.2. Creating a Problem Situation to Ask Questions. The typical feature of research learning theory is that there must be context to support the problem. The context must be organized, concise, and clear, and the way the problem is presented must be novel, in order to increase the novelty of the problem and stimulate students' interest. Teachers can use multimedia network classrooms to broadcast college physical education and network cinema functions and use courseware, stories, movies, and other forms to create problem situations to present problems, so as to better arouse students' active thinking.

4.2.1. Creating a Real Situation. Constructivist learning theory emphasizes the creation of real situations and regards creating situations as a necessary prerequisite for "meaning construction" and as one of the most important contents of college physical education design. Multimedia technology happens to be the most effective tool for creating real situations. If combined with simulation technology, it can produce more immersive and realistic effects. Teachers use the network environment with multimedia technology and network technology as the core to create situations that are as realistic as possible related to the subject, so that learning can occur in situations that are basically consistent or similar to reality.

Students learning in actual situations can stimulate students' associative thinking and stimulate their interest and curiosity in learning mathematics. Learners can use 
their original cognitive structure to assimilate and index the new knowledge they have learned so as to establish a connection between the new and the old knowledge and give the new knowledge a certain meaning.

4.2.2. Creating Life Scenarios. Life is the best classroom, and learning is also for a better life. Therefore, creating life situations in the classroom can not only cultivate students' practical ability but also effectively strengthen the connection between students and the reality of life, so that students can feel the existence of knowledge everywhere in life.

4.2.3. Creating Error Correction Scenarios. "Wrong is the precursor to the right." Students often make mistakes of one kind or another when solving problems. In this regard, teachers should create error correction scenarios for some obscure mistakes frequently made by students, guide students to analyze and study the causes of mistakes, find a good way to cure "mistakes," correct mistakes while knowing them, and prevent mistakes while correcting mistakes. They make up for students' shortcomings in knowledge and logical reasoning, improve the accuracy of problem-solving, and enhance the rigor of thinking. Discovery learning theory emphasizes that students' learning should be a process of active participation and discovery, rather than passively accepting knowledge. Students should be allowed to explore independently, find problems, and correct mistakes by themselves. It is necessary to create error correction situations and cultivate students' rigorous logical reasoning ability.

4.3. Analyzing and Solving Problems. According to learning needs, they analyze the subject of inquiry, formulate a subject learning plan (including determining goals, small group work, and planning progress), and organize cooperative learning groups to make full use of the functions and network environment in the multimedia network classroom. In the college physical education teaching at this stage of problem analysis, teachers should provide appropriate help and guidance, be good at selecting valuable questions or opinions among students, and guide students to discuss in order to find answers to questions. Teachers should allow students to think independently in specific operational activities, encourage students to express their opinions, and communicate with peers.

When teachers organize students' inquiry activities, they generally let students explore independently, think, and propose strategies and methods to solve problems. Because each student is a unique individual who constructs an understanding of knowledge in his own way, there must be differences between each student, and this difference is a valuable learning resource. However, the understanding of each student will also have limitations. Teachers need to organize the cooperation and exchanges between students and teachers and students on the basis of the students' personal opinions, so that different views can collide and learn from each other.
(1) Students can use the campus network and the Internet connected to the multimedia network classroom to collect materials, develop ideas, and conduct active and independent exploration of problems according to their needs. (2) The multimedia classroom group discussion, electronic forum, and other functions can be used to communicate and cooperate, so that students can analyze problems more abundantly and comprehensively and learn to cooperate with each other in the process. (3) Students browse related webpages and resources through browsers in a network environment, think about and analyze the information they have obtained, remove the false and keep the truth, and choose the best and eliminate the inferior. (4) They freely organize study groups according to their needs and carry out relevant collaborative learning activities (such as competition, debate, design, problem-solving, or roleplaying). (5) With the help of network tools such as NetMeeting, Internet Phone, ICQ, e-mail, Chat Room, BBS, and Blog, we can communicate with each other and participate in various types of dialogue, negotiation, and discussion activities.

According to the results of the analysis, students will be instructed to remove the false and preserve the truth, choose the best and remove the inferior, discuss with each other, draw the conclusion of the problem, and create a research report or electronic work related to the theme. The way to solve the problem and the innovation of the conclusion requires the educational wisdom of teachers and the imagination and creativity of students. The educational wisdom of teachers is to be good at organizing and managing the classroom. The cultivation and improvement of students' imagination and creativity require an open and relaxed environment.

The college physical education function of the multimedia network classroom not only provides teachers with a way to manage the classroom but also provides an environment where students can practice freely. The multimedia network classroom provides each student with a networked computer that can be operated independently, which can give full play to the specialties of individualization and interactivity. Students can independently participate in learning activities and can adjust the learning progress by themselves; teachers are in a network environment. Physical education in colleges and universities can use the broadcast function of the network to complete class collective teaching. It can realize cooperative learning between groups through online functions and communicate with students through monitoring/monitoring and control functions, making college physical education not only suitable for most students. At the same time, it also creates individual learning and development conditions for students of different levels. Therefore, it can be more conducive to the development of students' independent learning and exploratory learning.

(1) Students can use the group discussion, electronic forum, and other functions of the multimedia classroom to realize communication. (2) Students can express their conclusions in written form or verbally. (3) Students can use word processing software, spreadsheet software, and animation design software and can also use "geometric 


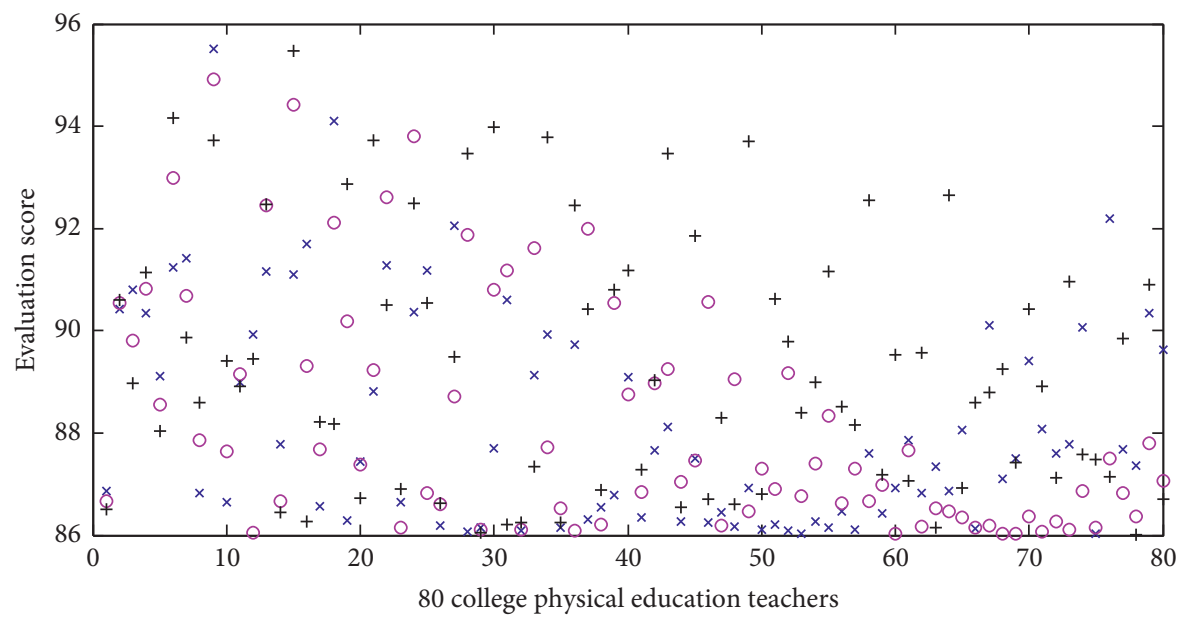

\footnotetext{
$\times$ Competent department staff

- Fellow teacher

+ Student
}

Figure 4: Evaluation subject scores based on 5G multimedia network teaching.

sketchpad," “drawing," "composition" tools, electronic manuscript production or web development, and other information "integration" tools to create works. (4) It can be sent to teachers and other students through network sharing, e-mail, or using the submission function of the multimedia network classroom.

\section{Research Results and Analysis}

\subsection{Analysis of Teaching Evaluation of Physical Education Teachers under $5 G$ Multimedia Network Technology}

5.1.1. Scoring Situation of the Evaluation Subject. The evaluation subject score based on $5 \mathrm{G}$ multimedia network teaching is shown in Figure 4. The main body of evaluation is the evaluation of students and the evaluation of personnel in the competent department. The evaluation mode is mainly the evaluation of the superior to the inferior and the evaluation of the students. Therefore, the teaching evaluation of physical education teachers does not solicit the personal opinions of physical education teachers and also ignores the evaluation of peer physical education teachers. Although students participate in the evaluation of physical education teachers, in fact, most physical education teachers do not pay much attention to students' feedback on the results of their college physical education evaluation results. This is due to the implementation of a centralized and unified administrative management system in education in my country (Figure 4).

5.1.2. Proportion of Evaluation Content. From Figure 5, the content of the teaching evaluation of physical education teachers is mainly based on the teachers' college physical education teaching attitude, college physical education teaching methods, athletic ability, moral quality, and college physical education teaching effects. In addition, it also includes the innovation ability of physical education teachers,

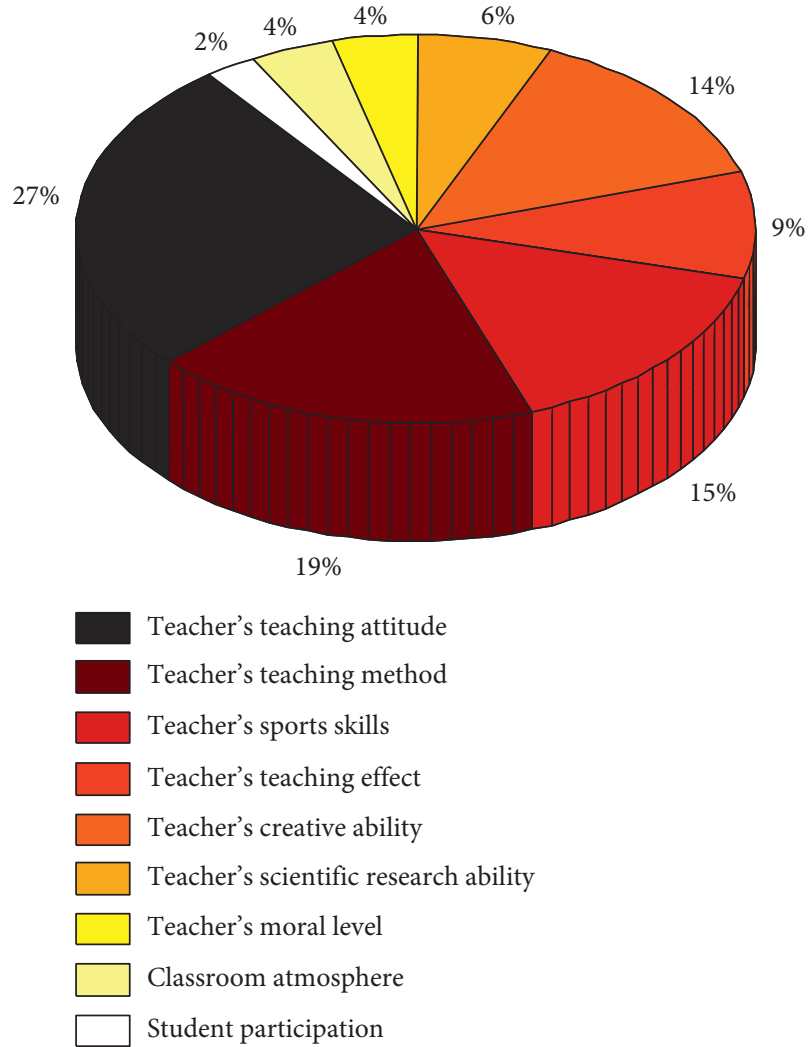

Figure 5: Evaluation proportion.

the scientific research ability of college physical education, the degree of student participation in the classroom, and the classroom atmosphere. Therefore, most physical education teachers focus on the meticulous design of college physical education and the application of college physical education skills and attach importance to the external work performance of teachers (Figure 5). 


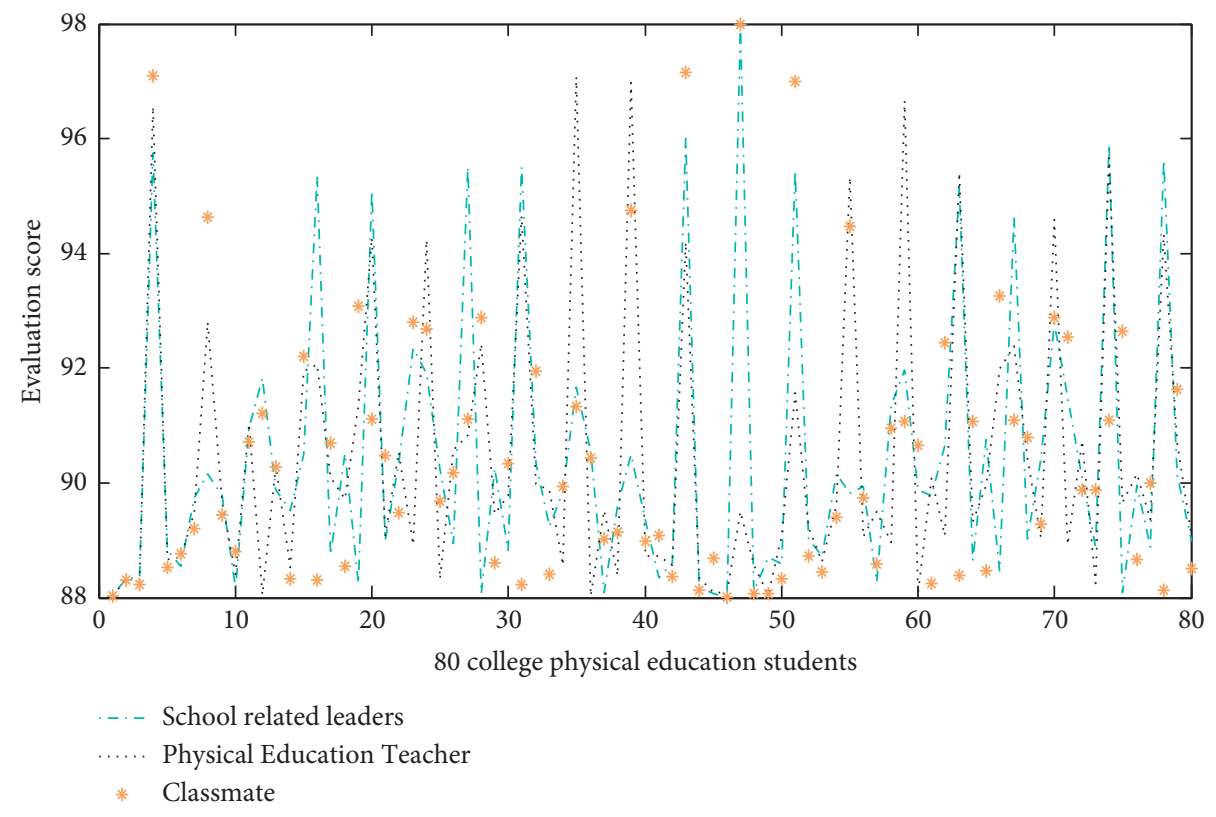

FIGURE 6: Evaluation subject scores based on $5 \mathrm{G}$ multimedia network teaching.

\subsection{Analysis of Student Evaluation of College Physical Education Teaching under $5 G$ Multimedia Network Technology}

5.2.1. Evaluation Subject's Scoring Situation. Figure 6 shows the evaluation subject scores based on $5 \mathrm{G}$ multimedia network teaching. The main body of the evaluation is physical education teachers, and the evaluation mode is mainly top-down evaluation, ignoring the possibility of student self-evaluation. Therefore, the evaluation of students' college physical education ignores the students' selfevaluation (Figure 6).

5.2.2. Proportion of the Evaluation Content. From Figure 7, the content of the evaluation of physical education teaching in colleges and universities for students is mainly based on theoretical knowledge of physical education, sports skills, classroom performance, and physical fitness. In addition, it also includes the evaluation of students' innovation ability, sports interest, and mental health level. Therefore, in addition to paying attention to some common content in the evaluation content, the differences of individual students should not be ignored (Figure 7).

5.3. Survey Results and Analysis of Physical Education Teachers' Teaching Evaluation Indicators under 5G Multimedia Network Technology. From Figure 8, the average of the three first-level indicators is above 89 , which is basically recognized by experts. Some experts suggested that the preparation of physical education in colleges and universities should take into account the physical teaching etiquette in colleges, teachers and students greet each other, and the habit of conscious exercise should be increased in the index of college physical education teaching
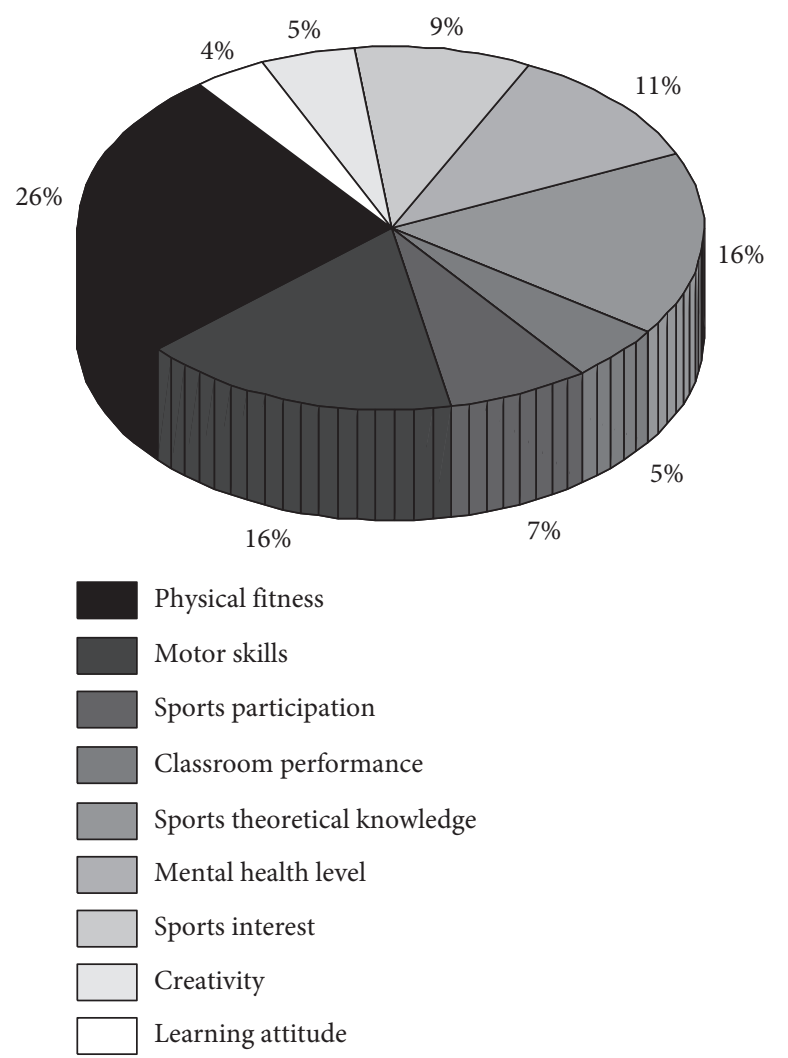

Figure 7: Proportion of evaluation content.

effect, and students' interest in sports should be increased. Moreover, the Kendall harmony coefficient in the first round is $0.061, P>0.05$, so the coordination degree of the expert index evaluation results is very low and inconsistent (Figure 8). 

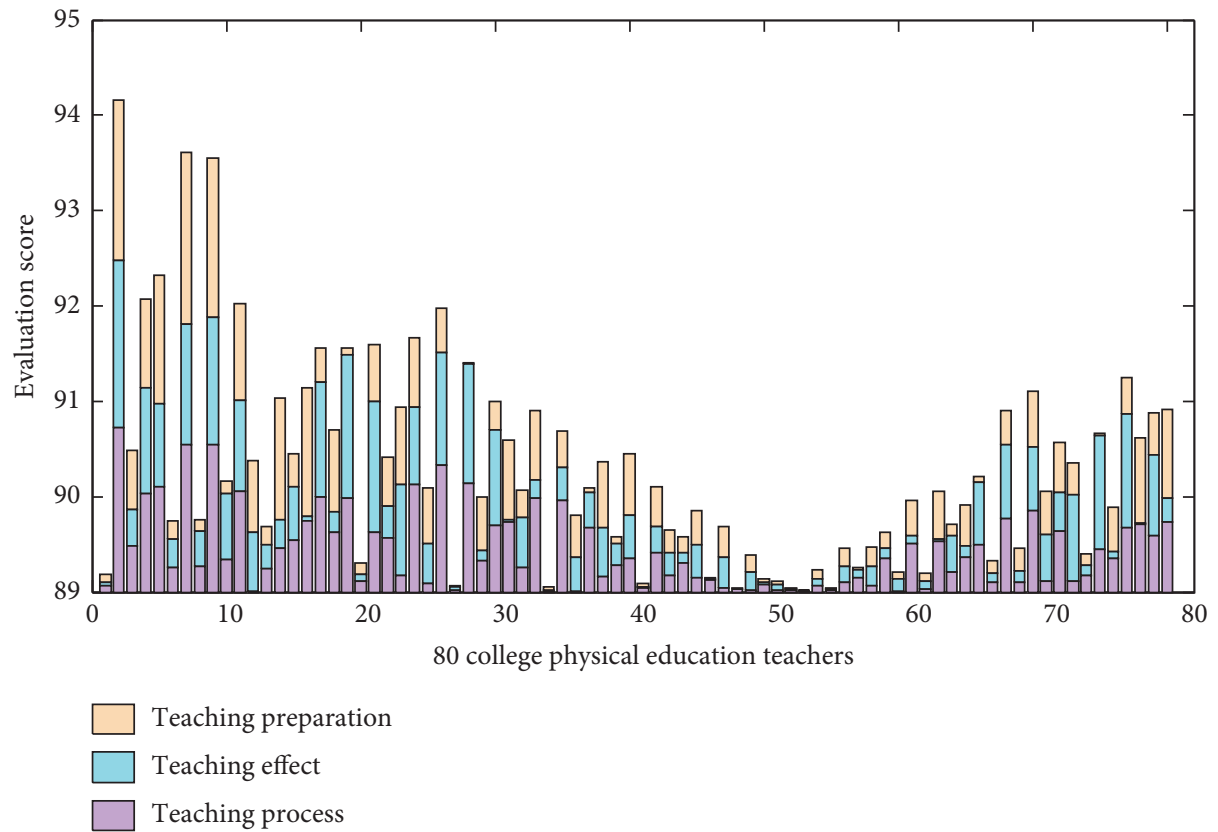

FIGURE 8: Scores of the first round of first-level indicators under 5G multimedia network technology.

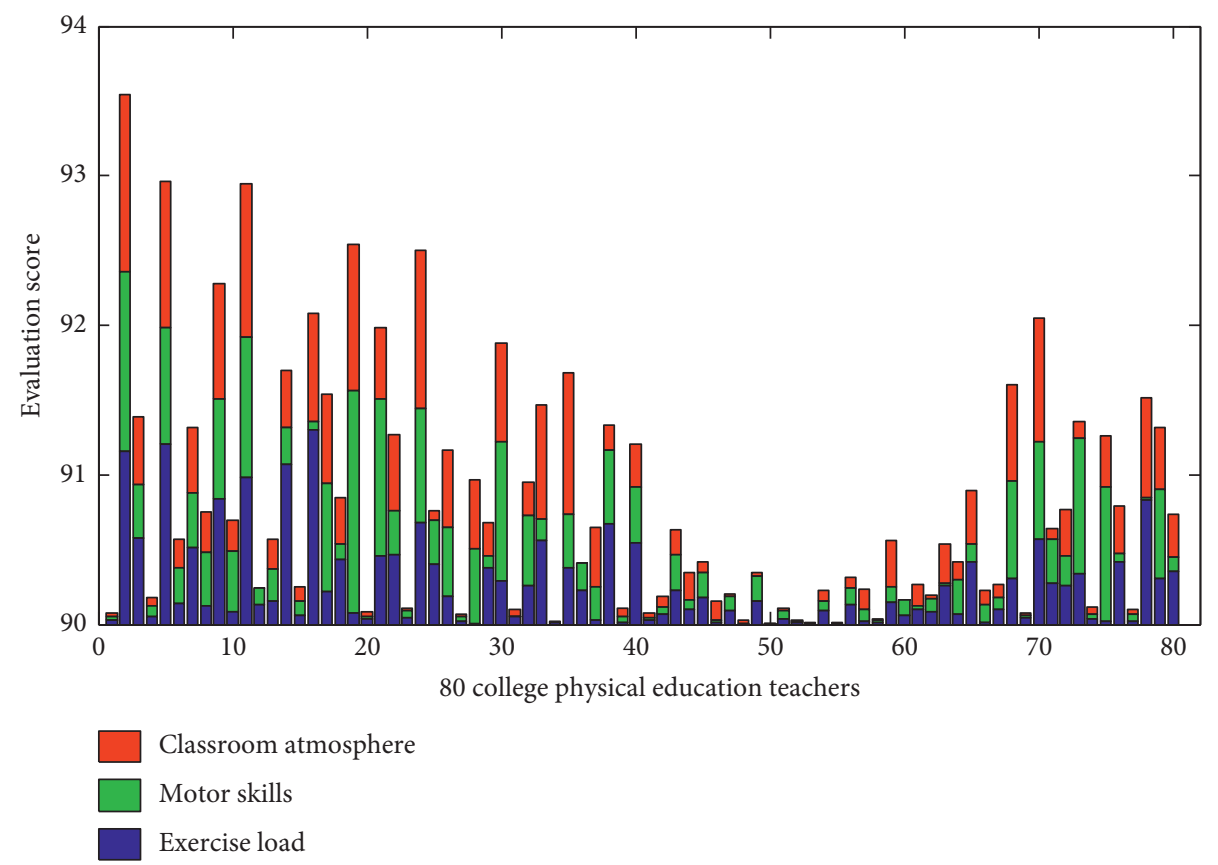

Figure 9: The first round of secondary index scores under 5G multimedia network technology.

As shown in Figure 9, the averages of the three secondary indicators in the first round are all greater than 90 , indicating that the initially designed secondary indicators have basically been recognized by experts. Some experts pointed out that the index of physical fitness includes the index of physical fitness, and these two should not exist side by side. The basic knowledge of sports theory also needs to be considered. The Kendall harmony coefficient is 0.087, $P<0.05$, indicating that the expert evaluation results are consistent but not highly coordinated (Figure 9).
5.4. Survey Results and Analysis of Evaluation Indicators for College Physical Education Students under 5G Multimedia Network Technology. From Figure 10, the averages of the three first-level indicators are all above 91, so they are basically recognized by experts. Among them, the average of the learning process is the highest, and the coefficient of variation is also the smallest, indicating the highest degree of recognition by experts; the coefficient of variation of learning preparation and learning effect is larger. Several experts have put forward suggestions on these two 


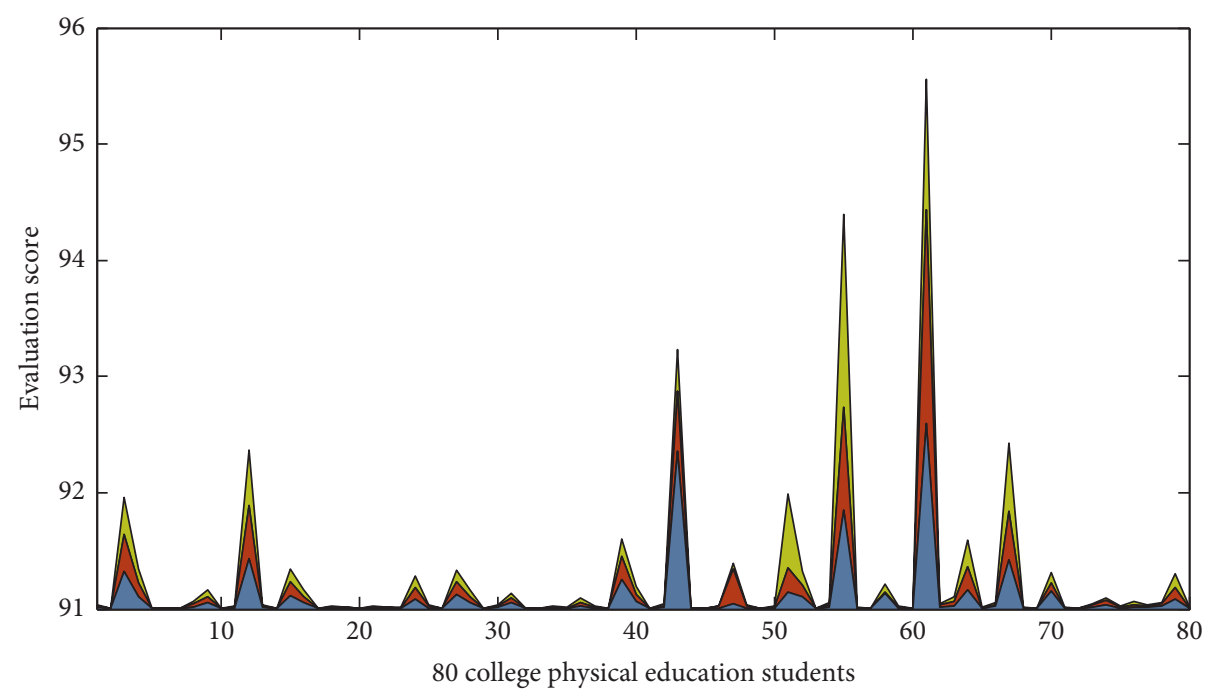

Learning result

Learning process

Study preparation

Figure 10: The first round of the first-level index score.

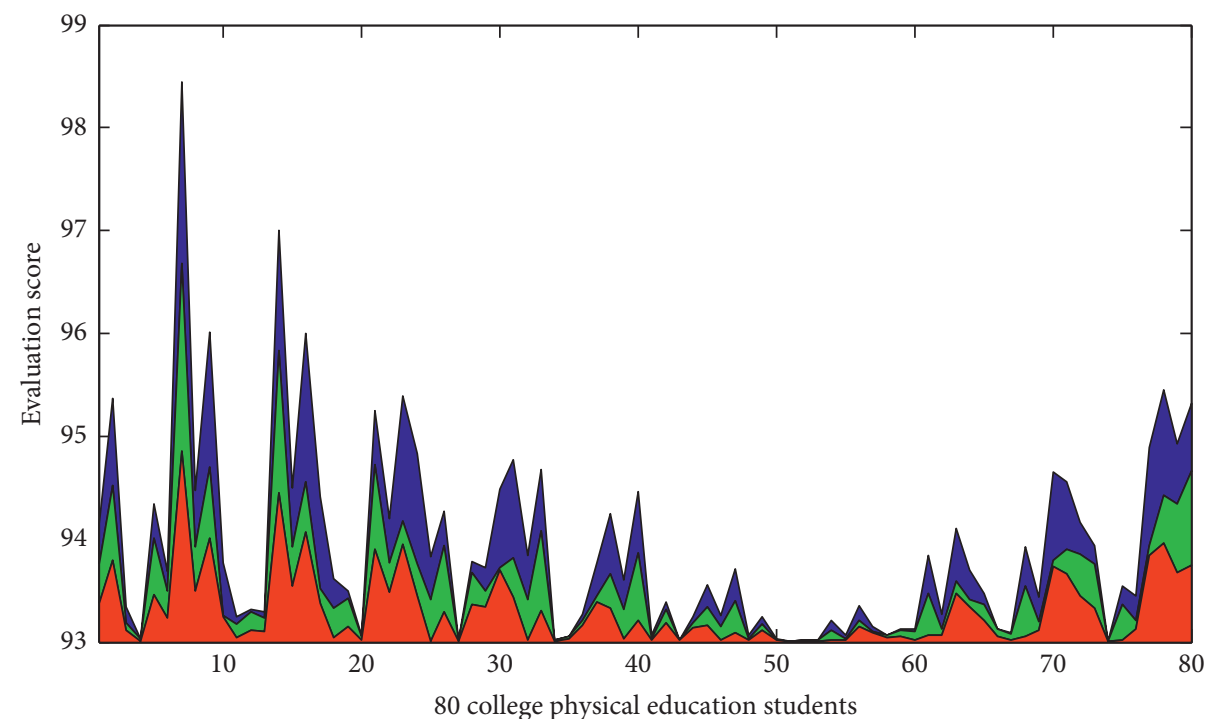

Team spirit

Theoretical basics

Learning attitude

FIGURE 11: Scores of the first round of secondary indicators.

indicators: college physical education teaching etiquette should be considered in the study preparation, hello to teachers, and learning effect indicators should increase the habit formation of students' conscious exercise and the degree of interest in sports. The Kendall harmony coefficient is $0.01, P>0.05$. Therefore, the coordination degree of the expert evaluation results is very low and inconsistent, and the indicators need to be further modified. Figure 11 shows that the average of the three secondary indicators in the first round of the survey is greater than 93, indicating that the primary design of the secondary indicators has basically been recognized by experts (Figures 10 and 11).

\section{Conclusion}

In order to solve the heterogeneity of the network, the model uses metapaths to capture the hidden structural information in the heterogeneous multimodal network and learns the 
node representation based on the network structure. In order to solve the sparsity of the network, the model uses an attention-based collaboration mechanism to integrate the structural representation of the node and the multimodal content representation, allowing them to complement each other to build a robust node representation. In the integration process, the attention mechanism is responsible for dynamically calculating the weights represented by different types of nodes for each node. The implementation of inquiry into college physical education in multimedia network classrooms can effectively influence and increase students' interest in learning, improve students' learning and practical ability, and provide necessary conditions for students to explore scientific knowledge courageously. Exploring the college physical education teaching model in the multimedia network classroom meets the requirements of the new curriculum that emphasizes students' independent exploration, cultivates students' innovative spirit and practical ability, and provides a way for the majority of educators to conduct college physical education in the multimedia network classroom environment. Under the background of the 5G multimedia network application, the main body of college physical education evaluation includes physical education teachers, students, peers, and personnel of college physical education departments. A combination of "selfevaluation-student evaluation-peer review-evaluation by the competent department personnel" is adopted for physical education teachers, and a combination of "self-evaluationgroup evaluation-teacher evaluation" is adopted for students; the evaluation index system is evaluated by physical education teachers. The index system and the evaluation index system of physical education teaching in colleges and universities are constituted. The evaluation of physical education teaching in colleges and universities lacks individuation and flexibility. Different evaluation systems should be constructed according to the professional differences of schools and colleges. For physical education teachers, the principle of differential treatment should also be adopted for college physical education. The evaluation process should be comprehensive, the evaluation process and evaluation results should be reflected, and the role of feedback should be emphasized. This article explores the construction of the evaluation system of physical education in colleges and universities, which can be used as a reference for the reform of the evaluation system of college physical education. However, due to technical limitations and feasibility, the selection of college physical education evaluation indicators is not comprehensive enough for the $5 \mathrm{G}$ multimedia network era, so its conclusions may have certain limitations and deficiencies.

\section{Data Availability}

The data used to support the findings of this study are included within the article.

\section{Conflicts of Interest}

The authors declare no conflicts of interest.

\section{References}

[1] X. Zhang and Q. Zhu, "Information-centric virtualization for software-defined statistical QoS provisioning over 5G multimedia big data wireless networks," IEEE Journal on Selected Areas in Communications, vol. 37, no. 8, pp. 1721-1738, 2019.

[2] Q. Jia, R. Xie, T. Huang, J. Liu, and Y. Liu, "Caching resource sharing for network slicing in 5G core network," Journal of Organizational and End User Computing, vol. 31, no. 4, pp. 1-18, 2019.

[3] S. Sukhmani, M. Sadeghi, M. Erol-Kantarci, and M. ElAbdulmotaleb, "Edge caching and computing in 5G for mobile AR/VR and tactile internet," IEEE MultiMedia, vol. 26, no. 1, pp. 21-30, 2018.

[4] M. Aazam, K. A. Harras, and S. Zeadally, "Fog computing for 5G tactile industrial internet of things: QoE-aware resource allocation model," IEEE Transactions on Industrial Informatics, vol. 15, no. 5, pp. 3085-3092, 2019.

[5] D. B. D. Da Costa, T. Q. Duong, M. A. Imran, H. Q. Ngo, N. Yang, and O. A. Dobre, "IEEE access special section editorial: modeling, analysis, and design OF 5G ultra-dense networks," IEEE Access, vol. 7, pp. 18894-18898, 2019.

[6] Y. Wu, A. Khisti, C. Xiao, G. Caire, K.-K. Wong, and X. Gao, "A survey of physical layer security techniques for $5 \mathrm{G}$ wireless networks and challenges ahead," IEEE Journal on Selected Areas in Communications, vol. 36, no. 4, pp. 679-695, 2018.

[7] N. Armando, R. Almeida, J. M. Fernandes, J. S. Silva, and F. Boavida, "End-to-end experimentation of a $5 \mathrm{G}$ vertical within the scope of blended learning," Discover Internet of Things, vol. 1, no. 1, pp. 1-12, 2021.

[8] B. B. Gupta, P. Chaudhary, and S. Gupta, "Designing a XSS defensive framework for web servers deployed in the existing smart city infrastructure," Journal of Organizational and End User Computing, vol. 32, no. 4, pp. 85-111, 2020.

[9] L. Sun and Q. Du, "Physical layer security with its applications in 5G networks: a review," China communications, vol. 14, no. 12, pp. 1-14, 2017.

[10] K. Zhang, S. Leng, Y. He, S. Maharjan, and Y. Zhang, "Cooperative content caching in $5 \mathrm{G}$ networks with mobile edge computing," IEEE Wireless Communications, vol. 25, no. 3, pp. 80-87, 2018.

[11] N. Saxena, A. Roy, and H. Kim, "Efficient 5G small cell planning with eMBMS for optimal demand response in smart grids," IEEE Transactions on Industrial Informatics, vol. 13, no. 3, pp. 1471-1481, 2017.

[12] A. Agarwal, K. Agarwal, S. Agarwal, and M. Gourav, "Evolution of mobile communication technology towards $5 \mathrm{G}$ networks and challenges," American Journal of Electrical and Electronic Engineering, vol. 7, no. 2, pp. 34-37, 2019.

[13] Y. Hong, M. Wan, and Z. Li, "Understanding the health information sharing behavior of social media users," Journal of Organizational and End User Computing, vol. 33, no. 5, pp. 180-203, 2021.

[14] U. O. Matthew and J. S. Kazaure, "Multimedia E-learning education in Nigeria and developing countries of africa for achieving SDG4," International Journal of Information Communication Technologies and Human Development, vol. 12, no. 1, pp. 40-62, 2020.

[15] J. Yan, D. Wu, H. Wang, and R. Wang, "Multipoint cooperative transmission for virtual reality in $5 \mathrm{G}$ new radio," IEEE MultiMedia, vol. 26, no. 1, pp. 51-58, 2018.

[16] T. Cao, C. Xu, J. Du et al., "Reliable and efficient multimedia service optimization for edge computing-based $5 \mathrm{G}$ networks: game theoretic approaches," IEEE Transactions on Network and Service Management, vol. 17, no. 3, pp. 1610-1625, 2020. 
[17] T.-H. Chou, "Exploring relationship quality of user's cloud service," Journal of Organizational and End User Computing, vol. 31, no. 3, pp. 17-36, 2019.

[18] K. Samdanis, A. Prasad, M. Chen, and K. Hwang, "Enabling $5 \mathrm{G}$ verticals and services through network softwarization and slicing," IEEE Communications Standards Magazine, vol. 2, no. 1, pp. 20-21, 2018.

[19] L. Feng, Z. Yang, Y. Yang, X. Que, and K. Zhang, "Smart mode selection using online reinforcement learning for VR broadband broadcasting in D2D assisted 5G HetNets," IEEE Transactions on Broadcasting, vol. 66, no. 2, pp. 600-611, 2020.

[20] C. Maican, A.-M. Cazan, R. Lixandroiu, L. Dovleac, and M. A. Maican, "Exploring the factors influencing the use of communication and collaboration applications," Journal of Organizational and End User Computing, vol. 33, no. 4, pp. 94-124, 2021.

[21] C.-C. Huang, "User's segmentation on continued knowledge management system use in the public sector," Journal of Organizational and End User Computing, vol. 32, no. 1, pp. 19-40, 2020.

[22] N. Ramu, V. Pandi, J. D. Lazarus, and S. Radhakrishnan, "A novel trust model for secure group communication in distributed computing," Journal of Organizational and End User Computing, vol. 32, no. 3, pp. 1-14, 2020.

[23] A. Aderonke, "Oni, ugbedeojo musa, samuel oni. E-Revenue adoption in state internal revenue service: interrogating the institutional factors," Journal of Organizational and End User Computing, vol. 32, no. 1, pp. 41-61, 2020. 